\title{
La Corte Permanente de Arbitraje y la recepción de su jurisdicción en México ${ }^{1}$
}

\section{Carlos Cerda Dueñas ${ }^{2}$}

Hoy, y qué bueno que así sea, la sociedad internacional tiene muy arraigados los conceptos de solución pacífica de las controversias y, como parte de ellos, el empleo de medios jurídicos, entendidos como la posibilidad de concurrir al arbitraje o al arreglo judicial en los numerosos y crecientes tribunales de jurisdicción internacional. Sin embargo, no siempre fue así. Cierto es que todo debe tener un inicio; en este sentido, esta ponencia pretender ilustrar cómo fue recibida, en su momento, una cuestión tan novedosa como lo era la jurisdicción del Tribunal Arbitral en diversos ámbitos de la sociedad mexicana.

El objetivo de la ponencia es rememorar un episodio de lo que ha sido la contribución latinoamericana a la jurisdicción internacional, pues, con ello, la sociedad latinoamericana ha aportado decididamente al desarrollo del Derecho Internacional, a través de lo que la convocatoria a esta III Conferencia Bienal señalaba respecto de nuestro hemisferio: "su postura firme y sostenida respecto a la obligación de solucionar las diferencias mediante métodos pacíficos y conforme a derecho".

El episodio referido es el caso de "El Fondo Piadoso de las Californias", primer litigio sometido a la resolución de la Corte, en 1902. Primeramente, se abordará el proceso histórico que devino en el establecimiento de la Corte Permanente de Arbitraje, seguido de los antecedentes históricos del caso en cuestión, para, en la parte final, analizar cómo se siguió el procedimiento en la opinión pública y la prensa de la época.

Es evidente que a este juicio no se le podía ignorar o adjudicársele indiferencia. Bien señalaba el abogado e historiador AlejandRo VILLASEÑOR Y VILLASEÑOR (1902, pp. 5-6),

1 Este documento fue elaborado en el marco del Seminario SLADI 2015. Para citar el artículo: Cerda Dueñas, C. (2016). La Corte Permanente de Arbitraje y la recepción de su jurisdicción en México, en Revista Con-Texto, n. ${ }^{\circ} 46$ EE, pp.11-29. DOI: https://doi.org/10.18601/01236458.n46EE.02

2 Abogado por la Universidad de Guadalajara; Maestro en Estudios Diplomáticos por el Instituto Matías Romero de Estudios Diplomáticos de la Secretaría de Relaciones Exteriores de México y Doctor en Derecho por la Universidad de Buenos Aires. Actualmente es Profesor en el Departamento de Derecho y Relaciones Internacionales del Tecnológico de Monterrey, Campus Guadalajara. Profesor Visitante en el Programa de Doctorado en Ciencias Penales en la Universidad San Carlos de Guatemala. 
en su obra publicada a propósito del juicio arbitral: "el Tribunal de Arbitraje formado con arreglo a los tratados celebrados en la famosa Conferencia de la Paz tenida en La Haya va a reunirse por primera vez con motivo de la reclamación hecha a México a propósito del llamado 'Fondo Piadoso de Californias'. Así, por el funcionamiento de ese Tribunal, novísimo en las prácticas del Derecho de Gentes, como por la clase de cuestiones jurídicas sometidas a él y por las personalidades ventajosamente conocidas en el mundo sabio y político que tomarán parte en los debates y en las decisiones del Tribunal, ese negocio de los Fondos de Californias, será célebre en los anales de la jurisprudencia internacional y su resolución es esperada con anhelo no sólo por México y los Estados Unidos que son los países interesados, sino por las demás naciones civilizadas".

\section{ANTECEDENTES DEL ESTABLECIMIENTO DE LA CORTE PERMANENTE DE ARBITRAJE}

Como es sabido, la Corte Permanente de Arbitraje (CPA) se gestó en la primera de las dos Conferencias Internacionales de la Paz de La Haya. El zar ruso NiCOLÁS II extendió una invitación a diferentes gobiernos, para que enviaran delegados a una conferencia en la cual habrían de considerarse cuestiones relativas al armamento y se concebiría un método para preservar la paz o contener la guerra. Uno entre tantos de los grandes méritos que se le atribuyen a estas conferencias es que fueron las primeras reuniones diplomáticas para tratar temas de paz sin referencia a alguna guerra en particular.

Con cartas fechadas el 24 de agosto de 1898, el zar extendió la invitación para que los delegados se ocuparan primordialmente del mantenimiento de la paz general y de una posible reducción del armamento. Esta conferencia, señalaba el escrito zariano, sería "con la ayuda de Dios, un feliz presagio para el siglo que está por comenzar. Convergería en un poderoso foco de atención para los esfuerzos de todos los Estados, los cuales buscan sinceramente imponer la gran idea del triunfo de la paz universal sobre los elementos de problemas y discordia" (Foster, 2004, p. 18). Los Estados Unidos y el Reino Unido, "las otras dos potencias de la época", consintieron la convocatoria rusa; no obstante, reconocían el amplío escepticismo respecto de sus posibles resultados. HerberT H.D. PIERCE, encargado de negocios de la legación norteamericana en San Petersburgo, envió un comunicado a la Secretaría de Estado, para señalar que "el consenso general de la opinión entre los miembros del Cuerpo Diplomático actualmente parece ser que la proposición es visionaria y utópica, hasta empapada de quijotismo" (Foster, 1904, pp. 15-16).

La conferencia se programó para iniciar el 18 de mayo de 1899, en la ciudad de La Haya, ciudad elegida por el zar, supuestamente para que no se realizara en San Petersburgo, que, en su parecer, era la capital de una de las grandes potencias de la época, y ello podría provocar desconfianza en algunos Estados. El embajador M. DE STAAL, representante ruso en la conferencia, señalaría durante su discurso de inauguración que la elección se debía a que la ciudad holandesa podría ser considerada "la cuna de la ciencia del Derecho Internacional", por su tradición y por las importantes negociaciones diplomáticas que en ella habían tenido lugar a lo largo de la historia. 
Desde enero de 1899, se dieron a conocer los temas de la agenda para la conferencia, entre ellos, la cuestión del desarme y la posibilidad de suscribir un acuerdo relativo a la solución pacífica de controversias internacionales. Dicho acuerdo, que finalmente se concretó, contempló el establecimiento de la CPA. Ya desde su preámbulo, pudo advertirse que los gobiernos representados en la conferencia estaban "deseosos de extender el imperio del Derecho y de fortalecer el aprecio por la justicia internacional", y que estaban "convencidos de que la institución permanente de una Corte de Arbitraje, accesible a todos, en el seno de las potencias independientes, contribuirá de forma efectiva a este resultado" (Foster, 1904, p. 40). La convención cuenta con cuatro grandes apartados o títulos: en uno, meramente introductorio, pero donde las partes declaran que se comprometen con el objeto de prevenir, tanto cuanto sea posible, el recurso a la fuerza en las relaciones entre Estados, las potencias signatarias acuerdan emplear todos sus esfuerzos para asegurar la resolución pacífica de las diferencias internacionales. El segundo título se refiere a los Buenos Oficios y la Mediación; el siguiente, a las Comisiones Internacionales de Investigación, y el cuarto, precisamente, es el relativo al Arbitraje Internacional, donde en 47 artículos, se establece la CPA y se definen su jurisdicción y los principios bajo los cuales se regirá, especificando la forma en la cual se elegirán sus miembros, las reglas del procedimiento, lo relativo a los laudos y otras cuestiones generales.

En lo referente al establecimiento de la CPA, no fue tan fácil. Existían ya antecedentes: la Unión Interparlamentaria, durante su reunión de 1894, adoptó una declaración a favor del establecimiento de una $\mathrm{CPA}_{\text {; }}$ al año siguiente, en la primera reunión de la Conferencia Mohonk ${ }^{3}$, hizo un pronunciamiento similar. La Barra de Abogados del Estado de Nueva York se pronunció (1896) en el sentido de la necesidad de un tribunal permanente, como rasgo esencial de cualquier esquema de arbitraje.

La I Conferencia de La Haya se realizó del 18 de mayo al 29 de julio de 1899. Durante los trabajos, "ningún proyecto fue bienvenido con mayor simpatía que aquel para el establecimiento de una Corte Permanente de Arbitraje" (BROWn SCOTT, 1920, p. 126). El delegado británico, sir JuLIAN PAUNCEFOTE, presentó en la sesión del 26 de mayo, la

3 La Conferencia del Lago Mohonk sobre Arbitraje Internacional fue fundada en 1895, con el propósito de fomentar y convencer a la opinión pública del arbitraje internacional de la conveniencia de suscribir tratados de arbitraje y el establecimiento de una corte internacional. La Primera Conferencia del lago Mohonk sobre Arbitraje Internacional se celebró en junio de 1895, en Lago Mohonk, condado de Ulster, Nueva York. Cincuenta estadounidenses eminentes fueron convocados por AlBERT K. SMILEY, propietario de la Casa de la Montaña del Lago Mohonk, uno de los resorts de verano más prestigiosos de la época. Las conferencias anuales pronto crecieron, hasta atraer a 300 líderes de gobierno, empresarios, religiosos, de los medios y del ámbito académico. Después de la muerte de AlBERT SMILEY, su medio hermano DANIEL SMILEY ocupó su lugar como anfitrión de las conferencias. La última conferencia se celebró en 1916. Se hicieron planes para la reunión que se celebraría en 1917, mas nunca se llevó a cabo. Durante la Primera Conferencia, el Comité de Negocios adoptó la siguiente resolución, presentada por el Dr. EDWARD Everett Hale: "Que se solicite al Presidente invitar a los gobiernos de Austria, Inglaterra, Francia, Alemania y Rusia a unirse a los Estados Unidos en el establecimiento de un Tribunal Permanente del más alto nivel, al que puedan ser sometidas a arbitraje, de tanto en tanto, cuestiones que surjan entre esos poderes". 
propuesta para el establecimiento de la Corte: "Si deseamos dar un paso adelante, creo que es absolutamente necesario organizar un tribunal internacional permanente que pueda reunirse instantáneamente ante la solicitud de las naciones en conflicto" (BROWN SCOTT, 1920, p. 126). Señaló que su propuesta se inspiraba, en gran parte, en las ideas planteadas por ÉDOUARD DESCAMPS ${ }^{4}$ en su obra Ensayo sobre el arbitraje.

El proyecto de PAUNCEFOTE fue adoptado como base de trabajo por el comité respectivo. La idea, sin embargo, tuvo detractores y opositores, particularmente el representante de Alemania, Dr. PHiLIPP ZORN, de la Universidad de Königsberg (hoy Kaliningrado), quien consideraba a la CPA como una "institución prematura y muy alejada de los objetivos originales de nuestros trabajos" (BROWN SCOTT, 1920, p. 129). Por su parte, el delegado italiano, Constantino Nigra, realizó una sólida defensa del proyecto, señalando que "la impaciencia con la que la opinión pública espera por los resultados de nuestros trabajos ha llegado a ser tan grande que sería muy peligroso rechazar un tribunal arbitral. Si la conferencia encontrara esta impaciencia con un non possumus, o fracasara en satisfacerla, sería realmente decepción culposa. En ese caso, la Conferencia incurriría en una grave responsabilidad con la historia, con las naciones y con su Majestad, el Emperador de Rusia" (BROWN SCOTT, 1920, p. 129). La mayoría de los delegados se manifestaba a favor, porque la necesidad de establecer la CPA se consideraba "no sólo en las altas esferas de los intereses de la humanidad sino también desde un punto de vista práctico y experimental" (BROWN SCOTT, 1920, p. 130).

Finalmente, la Conferencia de la Paz de 1899 adoptó la Convención que incluía la creación de la CPA, misma que fue modificada durante la II Conferencia, realizada en $1907^{[5]}$. En la circular enviada por el zar NiCOLÁs II a los países invitados, se contenían los temas a tratar, entre los cuales figuraban "las mejoras a hacerse a las provisiones de la Convención para la Solución Pacífica de las Controversias Internacionales, así como a la Corte de Arbitraje y a las Comisiones Internacionales de Investigación" (BROWN SCOTT, 1920 b, p. 396). También se planteaba que los ocho años transcurridos entre ambas conferencias "no solo han mostrado la necesidad de someter a una cuidadosa revisión las regulaciones preparadas en aquella ocasión, sino también han vuelto deseable el aumento y complemento de las instituciones entonces creadas para extender el campo de acción de la justicia internacional" (BROWN SCOTT, 1920, p. 325).

4 El chevalier ÉDOUARD DESCAMPS también se encontraba presente en la conferencia, pues fungía como miembro de la delegación belga. Fue senador y llegó a estar nominado al premio Nobel de la Paz. Durante las negociaciones para la creación de la Liga de las Naciones, propuso el establecimiento de una Corte de Justicia.

5 En la Conferencia de 1899, el único país latinoamericano presente fue México. Para la II Conferencia, en 1907, Latinoamérica estuvo representada por Argentina, Bolivia, Brasil, Chile, Colombia, Cuba, República Dominicana, Ecuador, Guatemala, Haití, México, Panamá, Perú, El Salvador, Uruguay y Venezuela. Estuvieron presentes delegados de la talla de Luis María Drago, Roque Sáenz PeÑa, Ruy Barbosa, Antonio Sánchez de Bustamante y Sirven, Francisco León de la Barra y José Pablo Torcuato BATLLE ORDÓÑEZ. 
La propuesta presentada contemplaba la creación de una Corte de Justicia Arbitral, "sin alterar el estatuto de la Corte Permanente de Arbitraje" (BROWN SCOTT, 1920, p. 388). Tras un largo debate, que se centró sobre todo en la eventual obligatoriedad del arbitraje, las delegaciones de la II Conferencia reformaron la Convención y, en lo referente a la CPA, acordaron que "con el objeto de facilitar el recurso inmediato al arbitraje para las diferencias internacionales que no se hayan resuelto por la vía diplomática, las Potencias Contratantes se comprometen a mantener, tal como fue establecida por la Primera Conferencia de la Paz, la Corte Permanente de Arbitraje, accesible en todo momento y que funcione, salvo estipulación contraria de las Partes" (Convención para la Resolución Pacífica de Controversias Internacionales, 1907, art. 41).

Actualmente, la CPA es una organización intergubernamental que cuenta con 115 países parte. Aunque fue concebida para atender solo casos concernientes a países miembros, en 1908 aceptó el caso Grisbårdana, entre Suecia y Noruega, aunque este último no había suscrito la convención respectiva. En 1930, la CPA conoció del caso Radio Corporation of America vs. China, siendo una disputa entre un Estado y una empresa. La CPA se ha tenido que actualizar, conforme han surgido nuevas reglas para el arbitraje, y también ante el surgimiento de numerosas instancias, tanto públicas como privadas, que ofrecen los servicios de arbitraje, así como el de otros tribunales con jurisdicción internacional que pueden resolver casos con la misma competencia que lo haría la CPA.

El establecimiento de una CPA, según se dijo en el ámbito de las Conferencias de la Paz de La Haya, era "la respuesta a las más altas aspiraciones de los pueblos civilizados, a aquellas ideas de progreso que han sido observadas en las relaciones internacionales y al desarrollo moderno del litigio internacional" (Brown Scott, 1920, p. 127).

\section{EL ASUNTO DEL FONDO PIADOSO DE LAS CALIFORNIAS}

Los misioneros Eusebio Kino, Juan María de Salvatierra y Juan de Ugarte se dedicaron a la evangelización de la lejana tierra novohispana llamada California, para lo cual requerían de la autorización y de los medios económicos que les permitieran conseguir su objetivo. Decidieron acudir a la autoridad civil y no a la eclesiástica, y tras varios intentos ante las autoridades reales y virreinales, obtuvieron la licencia respectiva que les condicionaba a conseguir, por sí mismos, los recursos financieros para no gravar al erario. Bajo este contexto establecieron, en febrero de 1697, el Fondo Piadoso de las Californias, que se fue constituyendo por donativos de dinero y de bienes muebles. Sin embargo, pronto comenzarían a adquirir inmuebles a título de administradores, toda vez que así lo disponían las restricciones que su orden religiosa aplicaba respecto de la tenencia de bienes temporales.

Cuando la Compañía de Jesús tuvo que salir de todos los territorios del reino español y sus colonias, por el decreto de 1767 expedido por CARLOS III, los franciscanos asumieron por breve tiempo el control de las misiones californianas, y en 1772, las cedieron a los dominicos. 
Al convertirse México en país independiente, asumió todos los derechos y bienes de la Corona; en consecuencia, se hizo de los bienes del fondo. Al secularizarse las misiones, en 1834, la administración del fondo recayó en el gobierno mexicano. Para 1836, la Santa Sede creó la diócesis de las Californias, por lo que el gobierno mexicano de José JoAquín HerRerA entregó las propiedades y los valores del fondo al obispo, quien se encargaría de administrarlos. Por la misma ley que dispuso lo anterior, se estipuló también una dotación de 6.000 pesos para el obispado. Esta situación prevalecería hasta 1842, cuando dicho ordenamiento legal quedó abrogado en función de que el presidente de México, entonces ANTONIO LÓPEZ DE SANTA, revocó las disposiciones previas sobre la administración del fondo, en un decreto por el cual se dispuso que sus bienes pasaran al gobierno mexicano, además de que se procediera a su venta y que el beneficio obtenido pasara al Tesoro Nacional, es decir, que se expropiaba el fondo, en el entendido de que se reconocería un adeudo de $6 \%$ anual del importe recaudado. Así, el 8 de febrero de 1842, el Gobierno tomó nuevamente la administración del fondo, y el 24 de octubre de ese año, se ordenó que se integrara al erario nacional y fuera administrado por la Secretaría de Hacienda. La mayor parte de la propiedad del fondo fue enajenada.

Don ANTONiO GÓmEZ ROBLEDO (1965), insigne internacionalista mexicano, señaló que el fondo constituía un importante ramo de la administración pública, directamente vinculado a la política interior del país, e igualmente a su política exterior, debido a que también se perseguía el fin de impedir que aquellas regiones, a causa de su pobreza y desamparo, corrieran la suerte de Texas.

En este contexto tuvo lugar la guerra de México y los Estados Unidos, que terminó con la suscripción del Tratado de Comercio, Amistad y Límites del 2 de febrero de 1848. Dicho instrumento, mejor conocido como Tratado de Guadalupe-Hidalgo, disponía, entre otras cosas, que también exoneraran los Estados Unidos a la República Mexicana de todas las reclamaciones de ciudadanos de los Estados Unidos no decididas aún contra el gobierno mexicano y que pudieran haberse originado antes de la fecha de la firma del tratado. Esta exoneración es definitiva y perpetua (GRISWOLD, 1990, pp. 192-193). No obstante lo señalado en el referido artículo, el 20 de junio de 1859, los obispos de Monterrey, Thadeus Amat, y de San Francisco, Joseph Sadoc Allemany (en 1850 fue erigida la diócesis de Monterrey, y tres años más tarde, la arquidiócesis de San Francisco) reclamaron como ciudadanos norteamericanos los derechos sobre el fondo desde 1847, alegando también ser los sucesores del primer Obispo de California en la parte territorial que ahora correspondía a los Estados Unidos. De hecho, en esta cuestión contaron con el apoyo del gobierno de Washington. Los gobiernos crearon entonces la Comisión Mixta de Reclamaciones, con representación de los dos países, que fracasó en su cometido respecto de este particular punto, por lo que se designó como árbitro a sir EDWARD THORNTON, embajador británico en Washington, quien con fecha 11 de noviembre de 1875, falló a favor de los religiosos norteamericanos. México cumplió rigurosamente con los pagos en 13 abonos anuales, pero los norteamericanos exigieron entonces el importe de los intereses generados después del período cubierto por el fallo de la Comisión de Reclamaciones (1869). México se negó a pagar, y tras varios años de 
infructuosas discusiones diplomáticas, se tomó la decisión de presentar el caso ante la recientemente creada CPA.

\section{EL TRATAMIENTO DEL ASUNTO DEL FONDO PIADOSO COMO EL PRIMER CASO DE LA CPA}

No es este el espacio para tratar con detalle los pormenores y vicisitudes del procedimiento arbitral. Valga, sin embargo, señalar que la CPA debería decidir, primero, si la mencionada reclamación de los Estados Unidos de América a favor del Arzobispo de San Francisco y del Obispo de Monterrey estaba regida por el principio de res judicata, en virtud de la sentencia arbitral pronunciada por THORNTON, y, segundo, de no estarlo, si la mencionada reclamación procedía.

El 22 de mayo de 1902, en la ciudad de Washington, se suscribió el acuerdo por el que las partes manifestaban su consentimiento para someterse a un tribunal arbitral. El tratado respectivo recibió el nombre de "Protocolo de Compromiso entre los Estados Unidos de América y la República de México para la decisión de ciertas cuestiones suscitadas con respecto al llamado Fondo Piadoso de las Californias". En el texto, se insertó que "las Altas Partes signatarias de este Compromiso, animadas de un vivo deseo de que la controversia así suscitada sea amigable, satisfactoria y justamente resuelta, han convenido en someter dicha controversia a la decisión de árbitros, quienes se ajustarán en todo lo que no se disponga de otro modo por el presente instrumento, a las prevenciones de la Convención internacional para el arreglo pacífico de controversias internacionales, comúnmente denominada 'Convención de La Haya" (SRE, 1903, p. 4). El instrumento fue suscrito por MANUEL DE AZPIROZ, embajador extraordinario y plenipotenciario de la República de México en los Estados Unidos de América, que, para tal efecto, se hicieron representar por JOHN HAY, secretario de Estado.

Este hecho fue registrado en la primera plana del The Washington Times, con el titular de "El primer tratado bajo la Convención de La Haya", que daba cuenta de que el día anterior se había suscrito, en la Secretaría de Estado, un tratado de "inusual interés", por el cual los Estados Unidos y México acordaban someter la "disputa" del Fondo Piadoso a un tribunal de árbitros integrado bajo las normas de la "Convención de la Paz". También refería que con mucha gratificación, se había expresado en los círculos oficiales la cuestión de considerar al Tribunal de La Haya de beneficio práctico para las dos naciones. De interés resulta también lo señalado en la nota en el sentido de que "el tratado no requiere aprobación de los Estados Unidos, pero debe ser ratificado por el Congreso mexicano que se encuentra actualmente en periodo de sesiones. Se requiere esfuerzo para que la Legislatura nacional mexicana actúe lo más pronto posible a efectos de que el caso pueda ser presentado ante el tribunal de La Haya en septiembre". La prensa mexicana lo publicitó hasta el día 24, El Correo Español y El Imparcial informaron de la suscripción, con textos casi idénticos, en función de que dependen en mucho de los cablegramas, lo cual explica también la dilación en la comunicación de las noticias.

En el contexto del juicio arbitral, la prensa estuvo al pendiente de los avances y acontecimientos que se generaban en el entorno. El Imparcial (6 de junio de 1902) dio 
cuenta del nombramiento de Emilio Pardo como el representante de México ante los reinos de Bélgica y los Países Bajos, señalando que "la decisión del gobierno de cubrir a la mayor brevedad el puesto de Ministro en Bélgica, obedece a la circunstancia de que, por primera vez, va a someterse al Tribunal de La Haya un asunto en que están interesados México y los Estados Unidos: la reclamación por obras pías que hace a nuestro país la iglesia de California". A la vez, informó que dicho nombramiento había sido ratificado por la Comisión Permanente del Congreso General ${ }^{6}$.

Retomando la cuestión del arbitraje, el presidente de los Estados Unidos de América designaría dos árbitros no nacionales, y el Presidente de México haría lo propio. Los norteamericanos nombraron como árbitros a sir EDWARD FRY, doctor en Derecho, quien había sido miembro de la Corte de Apelación y del Consejo Privado de la reina británica y, por lo tanto, era miembro de la CPA, y a FRIEDRICH MARTENS, doctor en Derecho, miembro del Consejo del Ministerio Imperial de Negocios Extranjeros de Rusia, y también miembro de la $\mathrm{CPA}^{7}$.

México designó como árbitros a T. M. C. ASSER, doctor en Derecho, miembro del Consejo de Estado de los Países Bajos y, en algún tiempo, profesor en la Universidad de Ámsterdam, y a JonkHEer A. F. DE SAVOrnin LOHMAN, doctor en Derecho, quien se había desempeñado como Ministro del Interior de los Países Bajos, profesor en la Universidad Libre de Ámsterdam y miembro de la Segunda Cámara de los Estados Generales. Ambos, miembros de la CPA. Estos árbitros eligieron, de conformidad con los artículos 23 y 24 de la Convención de La Haya, como "superárbitro" y presidente de derecho del Tribunal de Arbitraje, a HENNING MATZEN, doctor en Derecho, quien había fungido como profesor en la Universidad de Copenhague, Consejero Extraordinario en la Suprema Corte y Presidente del Landsting ${ }^{8}$. El Imparcial (22 de julio de 1902, p. 1) informó de los nombramientos de los árbitros (tomado de los Servicios de la Prensa Asociada y originado en Washington).

6 El Mundo Ilustrado, en su edición del domingo 15 de junio de 1902, también informó del nombramiento y consignó una semblanza, destacando que durante la Conferencia Panamericana, se le nombró Presidente de la Comisión de Arbitraje. Señaló, además, que el nombramiento conllevaba "una importantísima comisión ante el Tribunal de La Haya". Días más tarde, La Voz de México (22 de agosto de 1902, p. 2) informó que el 15 de agosto fue recibido en audiencia solemne por su majestad LEOPOLDO II, rey de los belgas, y agregó que "no pasarán muchos días sin que el Sr. Pardo se dirija a la capital de los Países Bajos, donde está acreditado con igual carácter de Ministro Plenipotenciario y tiene que desempeñar una misión especial ante el Tribunal Internacional de Arbitraje, residente en La Haya".

7 FrIEDRICH MARTENS O FRIEDRICH DE MARTENS, estonio de nacimiento, sirvió al Imperio Ruso y acudió como su representante a la I Conferencia de la Paz de 1899. Fue ahí que durante las negociaciones para la suscripción del Convenio relativo a las leyes y costumbres de la guerra terrestre, leyó una declaración que, a la postre, se insertaría en el preámbulo, y que hoy se conoce como Cláusula Martens, misma que establece que "mientras que se forma un Código más completo de las leyes de la guerra, las Altas Partes Contratantes juzgan oportuno declarar que, en los casos no comprendidos en las disposiciones reglamentarias adoptadas por ellas, las poblaciones y los beligerantes permanecen bajo la garantía y el régimen de los principios del Derecho de Gentes preconizados por los usos establecidos entre las naciones civilizadas, por las leyes de la humanidad y por las exigencias de la conciencia pública". Una de las cámaras que componían el Rigsdagen (Parlamento danés) fue suprimida en 1953. 
El hecho de que el caso del Fondo Piadoso fuera el primer asunto sometido a la jurisdicción de la CPA estuvo siempre presente. En los primeros días de septiembre de 1902, se inauguró el tribunal. El Presidente del Consejo Administrativo de la CPA tomó la palabra, para pronunciar un discurso y hacer explícito el hecho. Así, refirió que "después de la conclusión de la Convención se procedió enseguida a tomar las medidas necesarias para llevarla a cabo, de suerte que el 5 de enero de 1901 ya estaba todo listo para poner en vigor el sistema de Arbitraje. Los locales estaban preparados, los funcionarios de la Oficina Internacional estaban ya nombrados, los servicios organizados, un número suficiente de miembros de la Corte estaban designados y ya no se esperaba más que el caso que debía juzgar; pero como si no abundasen los motivos, los casos no se presentaban. Nadie quería inaugurar un nuevo procedimiento que todos habían juzgado ser el mejor" (SRE, 1903, p. 78). Por ello, "con un verdadero interés y con un sentimiento que casi podría decir de júbilo os acogemos, en nombre del Consejo Administrativo, en estos locales destinados al funcionamiento de la Corte Permanente de Arbitraje" (SRE, 1903, p. 77).

En un reconocimiento a las partes, indicó que "al Nuevo Mundo estaba reservado dar el ejemplo y despertar a la Vieja Europa que parecía adormecida, o por lo menos indiferente a este respecto. La gran República de la América del Norte y su vecina la de México, viendo que nadie se movía y que había el riesgo de que cayera en el olvido por falta de uso, una institución que ellas también habían contribuido a formar, se han puesto de acuerdo para hacer ver al mundo civilizado que no era vana quimera a la que se habían adherido al constituir esta Corte, sino que tenían la mira de hacer de ella un instrumento vivo de paz y de concordia encomendándole la solución de las diferencias de opiniones que existían entre ellas" (SRE, 1903, p. 78).

El acontecimiento generó expectación. Incluso, llegó a darse cuenta de que la reina Guillermina ofreció una cena a los miembros de la Corte de Arbitraje, al ministro de los Estados Unidos Newel y al ministro mexicano EMILIO PARDO, resaltando que "el diplomático americano ocupó el sitial de honor a la derecha de la Reina", refiriendo que "los otros huéspedes estuvieron discutiendo con gran interés los temas del arbitraje en general, mostrando un total aprecio por la Corte de Arbitraje que se encuentra sesionando aquí".

El lunes 15 de septiembre de 1902, se celebró la primera de once sesiones que habría de comprender este juicio arbitral. HenNING MATZEN, presidente del Tribunal, también hizo referencia a que se trataba del primer caso por resolver en la CPA. Así, en su primera intervención, señaló que "es la primera vez que se ha constituido un Tribunal de Arbitraje bajo el régimen de la Convención de La Haya sobre el arbitraje internacional (...). Este primer Tribunal está constituido, gracias a la iniciativa de dos grandes Potencias del Nuevo Mundo, que, animadas del mismo sincero deseo de arreglar amigablemente y de manera satisfactoria y justa una diferencia surgida entre ellas, se han puesto de acuerdo para someterla a un Arbitraje conforme en su esencia a las reglas de la Convención" (SRE, 1903, p. 80).

EMILIO PARDO, agente de los Estados Unidos Mexicanos, habría de señalar que "la gran institución creada por el Congreso de la Paz, es llamada por primera vez para prestar sus importantes servicios a la causa del Derecho y de la Justicia, y me apresuro a 
hacer patente la fe del Gobierno mexicano en la sabiduría, en la ciencia y en la imparcialidad del Tribunal que acaba de instalarse... Sea cual fuere para nosotros el resultado del juicio del Tribunal, podemos decir con el más legítimo orgullo, que como lo prueba la correspondencia diplomática cambiada entre los dos Gobiernos interesados para preparar la firma del protocolo del 22 de Mayo último, México fue el primero en proponer la aplicación del Arbitraje Internacional establecido por la Convención de 29 de Julio de 1899" (SRE, 1903, p. 84).

Entre tanto, en México, y como lo mandataba la Constitución, a la apertura de sesiones del Congreso de la Unión, se presentó el presidente, general Porfirio Díaz, el 16 de septiembre de 1902. En su intervención, informó a la representación legislativa que se había sometido al Tribunal Permanente de Arbitraje, creado "en virtud de la Conferencia justamente llamada de la Paz", el primer caso internacional contencioso, siendo las partes contendientes México y los Estados Unidos de América, explicando que después de algunas notas cambiadas entre el representante de los Estados Unidos y el Secretario de Relaciones Exteriores ${ }^{9}$, no se llegó a un acuerdo, porque la postura mexicana sostenía que el laudo de 1875 no comprendió los réditos posteriores, ni había fundamento para exigirlos o para considerar subsistente el capital. En función de lo anterior, informó que "se estipuló, con el espíritu de conciliación propio de naciones amigas, someter el caso a la decisión del tribunal de La Haya". Recordó que, para tal efecto, se firmó en Washington un protocolo de compromiso el anterior 22 de mayo, fijando las bases para el funcionamiento de ese tribunal. Señaló también que "el Gobierno mexicano confía en la muy reconocida honorabilidad y altas prendas de los jurisconsultos que componen tan respetable tribunal, y de nuevo ofrece acatar el fallo definitivo que se pronuncie en el asunto" (Diario de los Debates del Senado de la República, 1902, p. 11).

Todo el mundo diplomático y político tenía en esos momentos fijos los ojos en el Tribunal Internacional de Arbitraje de La Haya, en donde se estaba tratando un asunto de alta importancia, no tanto por el valor intrínseco de las reclamaciones que se discutían, sino por los precedentes que sentaría el fallo, cualquiera que fuera, en los anales de la diplomacia y de la historia internacional (La Vanguardia, 25 de octubre de 1902).

Si para toda nación culta debían ser interesantes los debates que se estaban verificando ante el alto tribunal de arbitraje, para México ese interés se duplicaba, pues era parte interesadísima en el asunto: nuestro país era el demandado, la instancia era la última, el fallo sería irrevocable y su acatamiento, inmediato, cual conviene a una nación que, como la nuestra, ha consolidado ya de manera precisa y definitiva su reputación de solvente y de respetuosa de sus compromisos. Un tribunal de competencia tan alta y de responsabilidad tan excepcional como el de La Haya. La actitud de México originó en Europa nuevas y vivas simpatías para nuestro Gobierno, que fueron mayores cuando se supo que él propuso someter el caso al Tribunal de La Haya, proposición que fue aceptada por los Estados Unidos.

9 Aurora Cortina GonZÁlez (1988, p. 238) señala que se canjearon "una larga serie de notas diplomáticas, en rebuscado lenguaje diplomático, que duró once años". 
La prensa mexicana siguió publicando periódicamente notas referentes al desahogo del juicio arbitral, llegando a publicar las memorias íntegras (El Popular, 19 de octubre de 1902). El Tiempo Ilustrado. Semanario Literario (20 de octubre de 1902) señaló ser el único diario que le concedió a ese asunto [el juicio arbitral] la atención que merece, "y para ilustrar la opinión, publicó una serie de artículos que han sido leídos con gran interés pues había muchas personas que ignoraban la historia de ese fondo piadoso y los antecedentes de la demanda de los Estados Unidos". Estos documentos, de la autoría de AlejandRo VilLaSEÑOR Y VILLASEÑOR ${ }^{10}$, se publicaron como fascículos $\mathrm{y}$, después, como libro, con el título Reclamaciones a México por los Fondos de Californias, que en 268 páginas, explica el motivo de la edición, debido a que "el Tribunal formado con arreglo a los tratados celebrados en la famosa Conferencia de la Paz tenida en La Haya va a reunirse por primera vez con motivo de la reclamación hecha a México a propósito del llamado 'Fondo Piadoso de Californias' (...), vamos a hacer la historia de esa reclamación para que nuestros lectores se formen idea de la importancia de ella y del interés que para México tiene" (VILLASEÑOR, 1902, p. 6).

El 14 de octubre de 1902, el Tribunal de La Haya emitió su laudo, determinando que la responsabilidad de México estaba establecida por el principio de res judicata, en virtud de la sentencia arbitral de sir EDWARD THORNTON, como árbitro de la Comisión Mixta de Reclamaciones, y que, en consecuencia, el Gobierno Mexicano estaba obligado a pagar a los Estados Unidos, para la jerarquía católica de California, la cantidad de 1.402.682, en cumplimiento de las anualidades que se habían acumulado desde 1869 hasta 1902, y que tenía la obligación adicional de pagar "a perpetuidad" una anualidad de 43.050 en moneda de curso legal en México. Así lo cumplió, aun en épocas de crisis económicas y turbulencias políticas que llegaron incluso a afectar de forma considerable la paz social del país.

El veredicto provocó reacciones y repercusiones en la prensa y en la opinión pública de ambas partes: en sus ediciones del 15 de octubre, The Washington Times reportaba "Victoria para los Estados Unidos en La Haya", en tanto que The San Francisco Call informaba que la victoria en la Corte de Arbitraje había sido de los Estados Unidos y la Iglesia Católica, señalando que el secretario Hay y otros oficiales de la Secretaría de Estado "se encontraban altamente gratificados y extremadamente esperanzados respecto del futuro de la solución de controversias internacionales a través del arbitraje".

A dos días de que se hiciera público el laudo, en México, las noticias concretas aun no llegaban, se limitaban a ser rumores. En este sentido, el diario El Tiempo (17 de octubre de 1902, p. 1) indicó: "Aun cuando ayer habíamos resuelto volver a ocuparnos del asunto, sino hasta no conocer completo el laudo pronunciado por el Tribunal de La Haya, la circunstancia de haber sido ampliados los primeros telegramas y de haber hablado por primera vez del asunto un periódico que puede estar bien informado, nos obliga a desistir

10 Nació en 1864 y murió en 1912, en la Ciudad de México. Estudió en la Escuela Nacional de Jurisprudencia. Fue miembro de la Sociedad Mexicana de Geografía y Estadística. Fundó los periódicos La Tribuna y La Lira. Colaboró también en El Tiempo. 
de nuestro primer propósito y a volvernos a ocupar del asunto, que es hoy el tema de todas la conversaciones en la ciudad, y que verdaderamente se ha hecho sensacional".

El fallo fue adverso para México, y es natural que generara reacciones encontradas, pero, sobre todo, de contrariedad en la sociedad. En tal sentido, se emitieron expresiones que bien la prensa hizo suyas o que fueron producto del parecer de dichos medios. "Esta sentencia del Tribunal de La Haya ha dado motivo a conversaciones y comentarios durante toda la semana; y los artículos de la prensa han menudeado estos días para dejar escapar toda la ira e indignación que el tal fallo ha despertado en todos los mexicanos" (El Tiempo Ilustrado, 20 de octubre de 1902).

En El Tiempo (22 de octubre de 1902), se señaló: "La opinión pública que por algunos años había permanecido en expectativa e indiferente a muchos de los sucesos que ocurrían en el país, está dando hoy, con motivo del fallo pronunciado por la Corte Permanente de Arbitraje de La Haya, una espléndida muestra de sus energías, así como del buen sentido del que está penetrada, elevando contra esa sentencia, un grito unánime, no de protesta, pero sí de indignación por la iniquidad del fallo".

No se puede negar que al ser la parte contraria los Estados Unidos, emergió el factor del nacionalismo, aún muy lastimado por la Guerra de 1847 y la correspondiente pérdida de más de la mitad del territorio nacional. Así, no fue extraño ver que muchas de las reacciones airadas tuvieran como fuente ese preciso hecho, que se trataba de los Estados Unidos, llegando incluso a desacreditar el trabajo de la Corte. Pero se trataba de la opinión pública, de los medios impresos, no del Gobierno, que si bien no estuvo del todo conforme con el fallo, siempre lo acató.

En este sentido, El Tiempo (22 de octubre de 1902) indicó que el "más respetable de los Tribunales de este mundo es una reunión de hombres más o menos sujetos a las influencias que el poder, la riqueza y las circunstancias desarrollan en cada caso". No obstante, el diario lanzó la sutil insinuación, en forma de interrogante, de qué habría sido de los Estados Unidos, pero el mismo periódico atenuó su dicho al añadir: "Esto no es acusar a los respetabilísimos jueces que tan fácil y prontamente se pusieron de acuerdo para fallar en lo principal, contra lo que nuestro gobierno ha sostenido; es simplemente reconocer que nada tienen de sobrehumano que, después de todo, pertenecen, como nosotros a la humanidad. Lejos de que nos asombre lo que han sentenciado, nos parece que han hecho un esfuerzo de imparcialidad bastante notorio, declarando que los réditos deben pagarse en plata, puesto que en plata estaba calculado el fondo, lo cual reduce dichos réditos a menos de la mitad de lo que pedían los Obispos".

Volvió a la carga el diario, al afirmar: "Juzgando, por lo que sabemos, y por el apresuramiento con que se ha prestado a conducirse, no podemos menos de ver en la resolución del Alto Tribunal, un expediente fácil y cómodo para salir de la dificultad tan breve como lo solicitaba el actor y sin correr el peligro de disgustarlo", pero volvió a atenuarlo y señaló que "la sentencia pudo haber sido peor; en efecto, si nuestros lectores han leído la historia del asunto, verán que el Tribunal de La Haya casi sentenció a México al mínimum de lo que contra él se pedía (...). Debemos pues felicitarnos, a pesar de la notoria injusticia de la que ha sido víctima México, de que los árbitros hayan cortado 
por lo sano, pues dadas las preocupaciones que tenían, pudieron habernos condenado a una enormidad que nos hubiera impuesto inmensos sacrificios".

Hubo crítica, hubo desconfianza, pero hubo respeto al Derecho y a las obligaciones que se generaron. El Imparcial señaló: "A pesar del descontento que el fallo ha causado, la mayoría se conforma con él, y lo único que irrita el orgullo nacional es esa renta perpetua que se mira como padrón de ignominia, y un impuesto pagado a los Estados Unidos y que da motivo a las más variadas y absurdas suposiciones y comentarios".

El diario The San Francisco Call (18 de octubre de 1902, p. 3) no pasó por alto la reacción de la prensa mexicana, y en nota titulada "Decisión provoca la ira de Editor", señaló la postura del "clerical" diario El Tiempo y sus ásperos comentarios a la decisión del Tribunal de La Haya, "como si el futuro de la Nación estuviera subordinada a ella". Destacó, por otra parte, la ecuanimidad del "liberal" Imparcial, a quien le atribuyó haber señalado que "prueba que los árbitros, altamente respetables y no superhumanos, han hecho un suficientemente meritorio esfuerzo para ser imparciales".

El Tiempo (22 de octubre de 1902) señaló, por su parte, que "en medio de esa indignación de quince millones de almas, no se ha escuchado ni un grito subversivo, ni una amenaza tonta, ni una nota discordante; la razón de esto es evidente: ese fallo se considera como un escarnio hecho a la justicia y al derecho de México, como un homenaje hecho a la fuerza, a la riqueza, al poder, a los cañones del poderoso; pero no se le ve como una calamidad nacional, pues afortunadamente México, al pagar antes del 14 de junio de 1903, fecha en que deberá pagar la suma a la que fue condenado, demostrará al mundo entero que su progreso es sólido".

Finalmente, un semanario alegaba que "México soportará a perpetuidad un gravamen injusto, exorbitante y enteramente inútil para el objeto para el que debería emplearse ese dinero" (El Tiempo Ilustrado, 20 de octubre de 1902).

El 22 de noviembre de 1902, el secretario de Hacienda, YVES LIMANTOUR, presentó una iniciativa de decreto ante la Cámara de Diputados, donde, fundado en el contenido del laudo de la Corte de La Haya de 14 de octubre, señaló que México debía pagar a Estados Unidos, en ocho meses contados a partir de la fecha del laudo, la cantidad señalada, para el 2 de febrero de 1903, y los réditos. Además, explicaba que "los honorarios de árbitros y abogados nombrados por el Gobierno mexicano y los pagos de traductores, taquígrafos, etc., habían alcanzado una suma aproximada de 73,000, cantidad ya pagada 'por decoro del país" (El Imparcial, 26 de noviembre de 1902), pero que se hacía necesario regularizar la operación y hacer las aplicaciones correspondientes en la cuenta del Tesoro.

El presidente de México, general PORFIRIO DíAZ, al inaugurar el segundo período del primer año de sus sesiones, el $1 .^{\circ}$ de abril de 1903, pronunció un discurso en el que se refirió al caso del Fondo Piadoso, señalando que el Gobierno de México había acatado el fallo definitivo del Tribunal de La Haya; que ya había sido cubierta la primera de las anualidades que, conforme a la sentencia, debían entregarse a los reclamantes por conducto del Gobierno de los Estados Unidos, y que en lo que concernía a los pagos futuros, una vez vencidos, serían también pagados. Pero vale la pena destacar, textualmente, que mencionó: "Así ha terminado este asunto, cuyo resultado, si bien en parte adverso para 
México, ha podido demostrar al mundo que hay medios pacíficos para el arreglo de las cuestiones internacionales" (Diario de los Debates, $1 .^{\circ}$ de abril de 1903, p. 336).

En su respuesta al Informe, el presidente del Congreso, Lic. JOAQuín D. CASAsús, también abordó el tema de la recurrencia a la CPA: "Más aún, habéis dado un ejemplo de los propósitos inquebrantables que animan a México para terminar pacíficamente las diferencias que pudiera tener con las demás naciones, sometiendo al Tribunal de Arbitraje de La Haya la reclamación que el Gobierno de los Estados Unidos de América formulara con motivo del llamado Fondo Piadoso de las Californias. El Poder Legislativo se congratula de que el laudo arbitral pronunciado en 14 de octubre del año pasado, haya sido cuando menos en parte favorable a los derechos de México; pero mucho más todavía de que haya sido acatado desde luego para demostrar la eficacia del Derecho Internacional, que no puede tener más apoyo que el respeto que las naciones civilizadas se deben las unas a las otras y el sentimiento de justicia, leyes ambas que rigen y gobiernan al mundo moral. El Congreso de la Unión no escatimará con tal motivo su aplauso a esa labor consciente y perseverante que hace de México, antes desgarrado por la discordia, un mensajero de paz, que lo pone en comunión íntima, con todos los pueblos por lejanos que de nosotros estén y que le hace representar, en el concierto de las naciones, el papel de repugnador de la causa noble del Derecho Internacional" (Diario de los Debates, 1. ${ }^{\circ} \mathrm{de}$ abril de 1903, p. 348).

Volvió a ocuparse del asunto, cuando rindió su informe general correspondiente a ese cuatrienio (1900-1904), al dirigirse a las cámaras del Congreso de la Unión, afirmando que aun cuando a juicio de su gobierno, se trataba de un hecho perfectamente esclarecido, el Ejecutivo convino en que las reclamaciones contra México fuesen sometidas a la decisión del Tribunal Permanente de Arbitraje que se radica en La Haya: "La República ha dado un ejemplo de cómo dos Estados pueden fácilmente resolver, por los medios pacíficos, sus mutuas diferencias internacionales". Además, reiteró la importancia, que se había considerado para todo el proceso, de las Conferencias de la Paz y el establecimiento de la CPA, por lo que declaró: "Basta recorrer las páginas anteriores, para formarse idea de la influencia que las convenciones de La Haya han tenido en las relaciones exteriores de los Estados, siendo muy satisfactorio consignar la correcta conducta observada por México en el exacto y fiel cumplimiento de los compromisos contraídos".

\section{EPÍLOGO}

La obligatoriedad del fallo y su indeclinable cumplimiento fueron aspectos que permearon sensiblemente en la opinión pública mexicana. Al año siguiente, en 1903, y ante el rumor de que Venezuela no cumpliría el laudo que emitió la Corte de Arbitraje en su segundo caso ${ }^{11}$, el diario El Imparcial (8 de septiembre de 1903, p. 1) publicó: "Justo

11 En diciembre de 1902, Venezuela declaró la moratoria de su deuda externa, situación que provocó que los gobiernos de los países a los que pertenecían los acreedores (Alemania, Inglaterra e Italia) bloquearan y atacaran las costas venezolanas con una escuadra integrada por veinte buques de guerra (cuestión 
es reconocer que, cuando se trató de la reclamación llamada del fondo piadoso de las Californias, por la cual México, según el fallo de la Corte Arbitral, hubo de pagar una suma considerable, la prensa mexicana de todos colores y programas, se apresuró a exponer los fundamentos que tenía México para rechazar la demanda; cuando llegó el fallo, hubo hasta comentarios más o menos duros para el tribunal y sus procedimientos, llegó hasta verse el caso curioso de que un periodista católico censurara muy acremente a los obispos reclamantes; pero justo es decir que no hubo entonces periódico mexicano que indicara la conveniencia de que México eludiera sus compromisos y dejara de acatar el fallo". Señaló el diario que esta actitud era, sin duda, muy digna del pueblo mexicano, como digna fue la actitud del Gobierno al cumplir sin reservas el compromiso contraído. Esto, en el parecer del diario capitalino, "viene a acentuar el contraste entre un pueblo disciplinado, ordenado ya, ansioso de respetar su nombre y conservar su prestigio".

El Tiempo, en su edición del 17 de octubre de 1902, argumentó que "para terminar de una vez, y no volver a acordarse del asunto, debería buscarse la manera de redimir esa renta de un golpe y no sufrir la vergüenza de verla figurar anualmente en nuestros presupuestos". Este mismo diario, un par de días después, reprodujo una carta que llegó a su redacción con una iniciativa de vecinos de la ciudad de Córdoba, Veracruz, para reunir la cantidad total y pagar todo en una sola exhibición, pues "con ello significaríamos cuánto nos lastima la sentencia que lamentamos, la cual deseamos sepultar en el olvido, como a los delincuentes que antaño se arrojaban al mar, con una bala enorme al pie" (El Tiempo, 22 de octubre de 1902). No obstante esas iniciativas, y como epílogo de esta cuestión, RiCHARD GRISWOLD DEL CASTILlO (1990, p. 158), historiador norteamericano, señaló que "el Gobierno mexicano pagó esta indemnización anualmente hasta 1914 cuando los pagos se suspendieron debido a las crisis diplomáticas generadas por la Revolución Mexicana", indicando que no fue efectuado ningún pago adicional a la cuenta del Fondo Piadoso hasta 1967, cuando, por mutuo acuerdo, México liquidó su "obligación perpetua", al hacer un pago final de 719.546 dólares, como un "acuerdo completo y definitivo de todas las reclamaciones".

Debe decirse que fue hasta la época en que gobernaba a México el presidente GuSTAVO DíAZ ORDAZ, que se pudo finiquitar este asunto, al obtener del gobierno norteamericano la cancelación del "adeudo". Las negociaciones diplomáticas para tal fin se celebraron entre el canciller mexicano, ANTONIO CARRILlo FlORES, y el embajador de los Estados Unidos, Fulton FreEMAN. El 1. ${ }^{\circ}$ de septiembre de 1967, el presidente informó al Congreso de la

que dio origen a la Doctrina Drago). El 13 de febrero de 1903, se levantó el bloqueo y se convocó a una reunión en Washington con la asistencia de las potencias agresoras, pero Venezuela no aceptó y, en consecuencia, el problema se sometió a la Corte Permanente de Arbitraje de La Haya, previa suscripción del compromiso respectivo y el desahogo del juicio arbitral. El fallo se emitió a favor de los países reclamantes, el 22 de febrero de 1904, señalándose que estos tienen derecho a un trato preferencial para el pago de sus créditos y que Venezuela, al haber consentido destinar un 30 por ciento de los ingresos de las aduanas de La Guaira y Puerto Cabello para el pago de las reclamaciones de todos los países, debía dar preferencia a los países actores en este caso. 
Unión que con un pago final de $716.546^{[12]}$ dólares, quedaba liquidado aquel, como le llaman algunos historiadores, "injusto compromiso"13.

\section{CONCLUSIONES}

Todo lo nuevo puede representar expectación, duda, incertidumbre y hasta temor. La sociedad mexicana pudo haber experimentado cualquiera de estos sentimientos hacia un tribunal arbitral radicado en un país extranjero, a miles de kilómetros de distancia, del que no se tenía antecedente alguno, puesto que era la primera vez que iba actuar.

Su creación y establecimiento se hizo bajo los más nobles y plausibles propósitos, como lo señalaba la Cancillería mexicana en la época: "Dicha Corte ha sido instituida por el acuerdo común de las Potencias que se han reunido por la generosa iniciativa del Augusto Soberano, Emperador de todas las Rusias, para disminuir en lo posible los horrores de la guerra y principalmente impedirlos, ofreciendo al mundo otra manera de resolver las dificultades y las cuestiones que pudieran surgir entre las naciones" (SRE, 1903, p. 77).

El Consejo Administrativo, a través de su presidente, en el acto de inauguración de la Corte, expresó enfáticamente que "una vez entablada la acción de la Corte Permanente de Arbitraje no cesará en tanto continúen existiendo entre las naciones causas de disentimiento, y que su intervención pedida por éstas, por su voluntad y sin imponerse por la fuerza a nadie, contribuirá poderosamente al mantenimiento de la paz del mundo" (SRE, 1903, p. 78).

Mucha crítica recibió la CPA en el momento de incoar y resolver el caso del Fondo Piadoso, sobre todo bajo el hecho de que se trataba de una cuestión eminentemente pecuniaria o por la cuestión de que los árbitros o agentes después fungirían con otro papel en otros casos.

Así, la controversia del Fondo Piadoso pasó a la historia, pero dejó un residuo de malos sentimientos entre los dos países. El enfoque litigioso de la jerarquía católica de California, con la colaboración del gobierno de Estados Unidos, continúa siendo interpretado por los historiadores mexicanos como una versión modernizada del Destino Manifiesto. La controversia del Fondo Piadoso también ilustra la actitud del gobierno mexicano hacia el arbitraje internacional: el gobierno mexicano tomó las decisiones de los tribunales internacionales y las comisiones de arbitraje como serias obligaciones y trabajó para acatar esas decisiones, incluso cuando estaban en contra de México (Griswold, 1990, p. 158).

12 La cantidad se determinó a partir del último año en que se pagó la anualidad, 1915, con los cálculos que realizó Rodrigo Gómez GómEz, director del Banco de México, tomando en cuenta las devaluaciones del peso mexicano (CORTINA, 1988).

13 Al parecer, existió un anteproyecto en tiempos del presidente ABELARDO L. RODRíGUEZ, que si bien era sobre la cuestión de El Chamizal, incluía una cláusula por la cual los Estados Unidos renunciaban a la reclamación del Fondo Piadoso, pero, al final, el gobierno mexicano no quiso que se relacionaran los dos casos. La negociación para finiquitar el asunto le correspondió a don ANTONIO CARrILLO FlORES, canciller de Díaz Ordaz (CorTina GonZÁlEZ, 1988, p. 241). 
México optó por la Corte de Arbitraje, en el contexto de la acuñación y socialización del concepto de la solución pacífica de controversias y de la creación de un órgano o medio jurisdiccional para la solución de esta clase de disputas. No lo dudó, y respetó y acató el fallo que siempre consideró injusto y desapegado a derecho. Esto quizá ha permeado en su ánimo, pues nunca más optó por volver a acudir a la Corte, pero no dejó de creer en el arbitraje, al que sometió diferendos ulteriores.

Con todo, la opinión pública y la prensa de la época siguieron atentamente todo este procedimiento, y siempre consideraron a la novel institución como una instancia idónea para el cumplimiento de sus objetivos, es decir, en términos de la convención que la establece, la resolución de controversias entre Estados por jueces de su propia elección y sobre la base del respeto a la ley. Ello debe considerarse un aporte de México, dentro de la región, al surgimiento y desarrollo de la jurisdicción internacional.

\section{FUENTES}

\section{a) Bibliográficas}

Brown, J. The Proceedings of The Hague Peace Conferences. The Conference of 1899. Nueva York: Oxford University Press, 1920, vol. 1.

Brown, J. The Proceedings of The Hague Peace Conferences. The Conference of 1907. Nueva York: Oxford University Press, 1920. vol. 3.

Cortina, A. El fondo piadoso de las Californias. En: Bernal, B. Memoria del iv Congreso de Historia del Derecho Mexicano, 1986. México: UNAM, 1988, t. I.

Foster, J. Arbitration and The Hague Court. Cambridge: University Press Cambridge, 1904.

Gómez Robledo, A. México y el arbitraje internacional. México: Porrúa, 1965.

Griswold, R. The Treaty of Guadalupe Hidalgo. A Legacy of Conflict. Norman: University of Oklahoma Press, 1990.

Merrills, J. International Dispute Settlement. Nueva York: Cambridge University Press, 2005.

PONCE, A. Historia de Baja California. De cueva pintada a la modernidad. Tijuana: Universidad Iberoamericana, 2004.

Secretaría de Relaciones Exteriores. Reclamación del gobierno de los Estados Unidos de América contra México respecto del Fondo Piadoso de las Californias. Documentos principales relativos. México: Imprenta de Francisco Díaz de León, 1903.

Villaseñor, A. Reclamaciones a México por los Fondos de Californias. México: Tipografía de "El Tiempo", 1902.

\section{b) Hemerográficas}

Al Sr. Lic. D. Emilio Pardo. En: El Tiempo. 18, junio, 1902.

Arbitrators for The Hague Court chosen. En: The Washington Times. 22, julio, 1902, p. 1.

Cablegramas: Holanda. En: La Patria de México. 17, abril, 1901, p. 2. 
Contestación al memorial sobre la reclamación presentada por el gobierno de los E.U. contra el de México relativa al llamado Fondo Piadoso de Californias. En: La Voz de México. 15, octubre, 1902, p. 1.

Conversaciones del lunes. En: El Tiempo Ilustrado. 20, octubre, 1902.

Decision stirs editor's wrath. En: The San Francisco Call. 18, octubre, 1902, p. 3.

El arbitraje entre México y Estados Unidos. En: El Imparcial. 22, julio, 1902.

El Arbitraje y México. En: El Imparcial. 24, mayo, 1902, p. 2.

El Fondo Piadoso de las Californias. En: El Imparcial. 26, noviembre, 1902.

El Fondo Piadoso de las Californias: protocolo de compromiso entre México y Estados Unidos. En: El Tiempo. 12, septiembre, 1902, p. 1.

El nuevo ministro de México en Bélgica. En: El Mundo Ilustrado. 15, junio, 1902.

El primer fallo del Tribunal de La Haya. En: La Vanguardia. 25, octubre, 1902, p. 1

El proyecto de arbitraje. En: El Correo Español. 6, enero, 1902.

El Sr. Lic. Emilio Pardo. En: El Tiempo Ilustrado. 9, junio, 1902.

First treaty under The Hague Agreement. En: The Washington Times. 23, mayo, 1902.

Informe de Gobierno. En: Diario de los Debates del Senado de la República. 16, septiembre, 1902, pp. 9-21.

Informe de Gobierno. En: Diario de los Debates del Senado de la República. 1, abril, 1903, pp. 335-350.

La Conferencia de La Haya. En: La Patria de México. 19, mayo, 1899, p. 1.

La Conferencia de la Paz. En: El Tiempo. 16, junio, 1899.

La Conferencia de Paz. En: El Mundo. 20, junio, 1899.

La Conferencia del Desarme. En: El Popular. 10, junio, 1899.

La Corte de Arbitraje de La Haya. En: El Tiempo. 25, octubre, 1902, p. 1.

La cuestión del Fondo Piadoso de las Californias. En: El Popular. 19, octubre, 1902, p. 1.

La legación de México en Bélgica. En: El Imparcial. 6, junio, 1902, p. 1.

La Sentencia del Tribunal de La Haya. En: El Tiempo. 17, octubre, 1902.

La sentencia del Tribunal de La Haya. (1902, octubre 22). El Tiempo.

Las Conferencias de La Haya. En: El Correo Español. 6, marzo, 1899.

Las Conferencias de la Paz. En: El Imparcial. 2, junio, 1899.

Las Conferencias de la Paz. En: El Mundo. 21, mayo, 1899.

Los Fondos Piadosos de California. En: La Voz de México. 3, septiembre, 1902, p. 2.

Méjico en El Haya. En: El Correo Español. 17, octubre, 1903.

Notes of the passing day. En: The Mexican Herald. 17, junio, 1902, p. 8.

Noticias Varias. En: La Voz de México. 22, agosto, 1902, p. 2.

Nuestro ministro en Bruselas. En: El País. 17, junio, 1902, p. 1.

Pious Fund arbitration. En: The New York Times. 16, septiembre, 1902.

President works for peace. En: New York Tribune. 25, septiembre, 1904, p. 1.

Queen gives dinner. En: The Mexican Herald. 27, septiembre, 1902.

Reclamación contra Méjico. En: El Correo Español. 24, mayo, 1902.

Sign the Convention. En: The Mexican Herald. 24, mayo, 1902, p. 1. 
United States and the Catholic Church win victory in the Court of Arbitration. En: The San Francisco Call. 15, octubre, 1902.

Varias Notas. En: La Voz de México. 1, junio, 1902.

Varias Noticias. En: La Voz de México. 14, junio, 1902.

Victory for the United States at The Hague. En: The Times. 15, octubre, 1902, p. 3.

\section{c) Electrónicas}

Convención de 1899 para la Resolución Pacífica de Controversias Internacionales. Julio 29 de 1899 [en línea]. Disponible en internet: http://www.ordenjuridico.gob.mx/JurInt/PA1.pdf

Convención de 1907 para la Resolución Pacífica de Controversias Internacionales. Octubre 18 de 1907 [en línea]. Disponible en internet: http://www.ordenjuridico.gob.mx/JurInt/PA2.pdf

Informe del C. General Porfirio Díaz, Presidente de los Estados Unidos Mexicanos, a sus compatriotas, acerca de los actos de su Administración en el período constitucional comprendido entre el $1^{\circ}$ de Diciembre de 1900 a 30 de Noviembre de 1904 [en línea]. Disponible en internet: http://www.memoriapoliticademexico.org/Textos/5RepDictadura/1904Inf-PD.html 